\title{
Multiple climate hazards in Eurasian drylands
}

\author{
Masato Shinoda ${ }^{1} \cdot$ Troy Sternberg $^{2} \cdot$ Banzragch Nandintsetseg $^{1,3,4}$
}

Received: 22 October 2018 / Accepted: 22 October 2018 / Published online: 13 November 2018 (c) Springer Nature B.V. 2018

Drylands occupy $41 \%$ of the earth's landmass and are home to more than two billion people-the majority of whom live marginal, climate-dependent lives. In Asia, the continent with the largest dryland extent, climate hazards comprise $87 \%$ of disaster events. Led by drought and floods, hazards also include extreme cold, heatwaves, and dust-forces which, when influenced by human activity, can exacerbate degradation and desertification and have detrimental impact on livelihoods and societies. Scientific projections show that in many regions of the world the frequency of extreme climatic events is increasing and that this trend will continue. This poses a particular threat to the inhabitants of drylands whose livelihoods most often depend on agriculture and livestock rearing. The projected increase in the frequency of various types of extreme weather events presents a great challenge in such vulnerable social-environmental system.

Vast Asian drylands arc from the Middle East to Mongolia and northeast China. In particular, Eurasian mid-high-latitude drylands present a harsh environment with a cold, arid climate. The livelihoods of the people inhabiting the steppe and desert environment have long been jeopardized by the repeated occurrence of natural hazards associated with such a climate. Events can be characterized as the "4Ds": drought, dzud (severe winter conditions), dust storms, and desertification, processes which occur interactively. However, previous attempts to clarify disaster mechanisms and efforts to implement appropriate land management techniques have been unsatisfactory. Typically, efforts have focused on individual disasters rather than understanding how hazards interact, with outcomes often exacerbating disasters.

Recently, a new approach focusing on multiple hazards has been evolving within disaster science. Motivated by the UN Agenda 21 for Sustainable Development, the process calls for "complete multi-hazard research" that works to integrate human settlement planning and management in disaster-prone areas. Given this context, disaster management authorities responsible for making effective decisions for specific geographic areas should consider all spatially relevant hazards. Awareness of an increase in various types

Troy Sternberg

troy.sternberg@geog.ox.ac.uk

1 Nagoya University, Nagoya, Japan

2 Oxford University, Oxford, UK

3 Information and Research Institute of Meteorology, Hydrology and Environment, Ulaan Baatar, Mongolia

4 National University of Mongolia, Ulaan Baatar, Mongolia 
of extreme weather that is likely to continue, and the crucial absence of a multi-hazard approach, motivated this special issue of Natural Hazards to better understand the interactive nature of multi-hazards and to encourage an interdisciplinary approach. This knowledge can establish a disaster management framework and provide practical management applications.

This special issue identifies climate hazard dynamics such as droughts and $d z u d s$ (extreme winter) and dust storms, and their interactions in Eurasian drylands with a focus on Mongolia. Papers address methodology for estimating the risk of hazards and developing an early warning system of meteorological disasters for their proactive and integrated management. Research assesses climate data and uses satellite techniques and models, interviews, and mapping to identify multiple hazard risk in Eurasia. Several articles address the most significant regional disaster, the 2009-2010 extreme winter, including possible links to drought, air mass formation and advection, herder vulnerability, covariate risk, disaster preparation and management. Further, dust dynamics and hazard relation to rangelands, vegetation, soil and dust erodibility, and snow cover are explored with novel findings that mark regional differences from general dryland trends.

The issue includes achievements from the recent project "Integrating Dryland Disaster Science" that was implemented from 2013 to 2017 under the Grants-in-Aid for Scientific Research Program supported by the Japan Society for the Promotion of Science. Hosted by Nagoya University (Japan), partners included Tottori University (Japan), the Japan Agency for Marine-Earth Science and Technology (Japan), the National Agency for Meteorology, Hydrology and Environment (Mongolia), and Oxford University (UK). The diverse collaborators have contributed to this original special issue that for the first time stresses how multiple climate hazards interact across Eurasian drylands. 